\title{
POSTPRINT
}

\section{Semantic stability in derivationally related words}

\author{
Renate Raffelsiefen \\ Freie Universität Berlin
}

\section{Introduction ${ }^{1}$}

In this paper I investigate the significance of stability of the semantic relation between etymologically related words over historical time. Such semantic stability can be shown to be determined by certain aspects of phonological transparency exhibited by the cognates (cf. Raffelsiefen 1993). These transparency conditions refer to the surface phonological form of words, which argues against abstract underlying forms and phonological rule systems based on "alternations".

\section{Semantic stability as a window on the acquisition of word meaning}

The notion of "semantic stability" refers to a relation between words as is shown in (1):

\author{
OHG faran \\ 'to move along' (e.g. walk, \\ swim, fly, etc.) \\ NHG fahren \\ 'to ride (in) a vehicle (with \\ wheels)'
}

\author{
OHG fart \\ 'moving along' (e.g. walking, \\ swimming, flying, etc.)<smiles>[AlH2]</smiles> \\ NHG Fahrt \\ 'riding (in) a vehicle (with \\ wheels)'
}

\footnotetext{
${ }^{1}$ I thank Mike Brame, Gabriel Falkenberg, Pieter Muysken, Bruce Straub, Heinz Vater, and Theo Vennemann for comments and inspiring discussions. The report by an anonymous referee drew my attention to several potential misunderstandings. This work was funded in part by the Sonderforschungsbereich "Theorie des Lexikons" (Deutsche Forschungsgemeinschaft).
} 
Over the last millennium the change in meaning of the German verb fahren has been mirrored by corresponding changes in the meaning of its cognate Fahrt. ${ }^{2}$ The pair fahren $\sim$ Fahrt is therefore semantically stable. Semantic instability will - should the meaning of one of the cognates change manifest itself in semantic drift as is illustrated by the cognates in (2): ${ }^{3}$

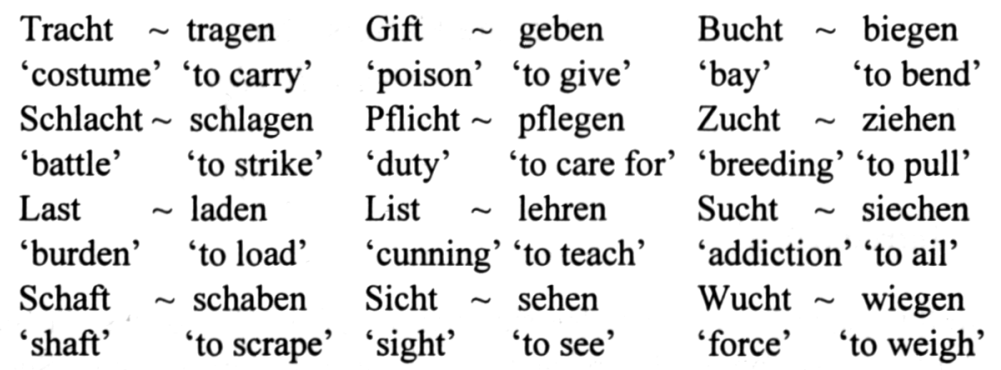

The nouns in (1) and (2) are historically derived by the same suffix. Yet while German speakers clearly associate Fahrt and fahren, they typically do not consider the cognates in (2) to be related.

While semantic stability refers to relations between words over historical time, it also provides insight into the synchronic mechanisms for acquisition of word meaning. Semantic stability between two words A and B implies that, generation after generation, learners have interpreted $\mathrm{A}$ in terms of $\mathrm{B}$. That is, the meaning they have assigned to $\mathrm{A}$ has consistently been based on the meaning of B. The question is why learners of German have consistently interpreted Fahrt in terms of fahren? Why do they no longer interpret Tracht with reference to tragen?

To answer these questions I will explore the observation that phonological and semantic transparency are correlated, as is shown in (3):

$$
\begin{array}{ll}
\text { [fa:rt }]=[\text { fa:rən }] & \text { [traxt } \neq \neq \text { [tra:gən] } \\
\text { Fahrt } \rightarrow \text { fahren } & \text { Tracht }{ }^{*} \rightarrow \text { tragen }
\end{array}
$$

The shafted arrow " $\rightarrow$ " refers to meaning relations between words and is defined as follows:

\footnotetext{
${ }^{2}$ The claim that the meaning of Fahrt consistently mirrors the meaning of fahren through historical time is also supported by more specialized uses of fahren. Fahren is for instance used for riding a sled (i.e. Schlitten fahren), and this use is also reflected in the noun Fahrt (i.e. die Fahrt mit dem Schlitten).

${ }^{3}$ A frequent consequence of semantic instability is the development of concrete meanings of formerly abstract nouns (cf. Tracht, Schaft, Gift, Bucht).
} 


$$
\mathrm{A} \rightarrow \mathrm{B} \quad \mathrm{A}^{*} \rightarrow \mathrm{B}
$$

$A$ is interpreted in terms of $B \quad A$ is not interpreted in terms of $B$

The notion "phonological transparency" refers to sameness of surface structure and is defined as follows: ${ }^{4}$

(5) Two words A and B are phonologically transparent if one word is a substring of the other (disregarding inflectional affixes). Here we ignore phonological differences which are conditioned either by the position of a speech sound within the syllable or by coarticulation.

By way of illustration consider the speech sounds $\left[\mathrm{r}^{\mathrm{x}}\right]$ and $\left[\mathrm{r}^{\mathrm{y}}\right]$ in (6a). Although any phonetician will attest to the clear distinctness of these sounds, they are still perceived to be "the same" sound. The phonetic difference between them is due to the fact that $\left[\mathrm{r}^{\mathrm{x}}\right]$ occurs in coda position whereas $\left[\mathrm{r}^{\mathrm{y}}\right]$ occurs in onset position. According to the definition in (5) this difference does not affect phonological transparency. By contrast, the phonetic differences between the words in (6b) cannot be ignored according to the definition in (5) as a result of which that pair is perceived as phonologically opaque.

(6)
a. $\left[\right.$ fa:r $\left.^{\mathrm{x}} \mathrm{t}\right] \sim\left[\mathrm{farr}^{\mathrm{y}} \mathrm{an}\right]$
b. [traxt] [tra:gən]

Note that the frequency with which a phonological alternation occurs does not affect transparency judgments according to the definition in (5).

The correlation between phonological and semantic transparency observed in (3) suggests the following empirical claim:

(7) The relation between an abstract noun and its (etymological) base is semantically stable as long as phonological transparency is satisfied.

The claim in (7) follows from the acquisition model illustrated in (8). A learner encountering a new word, say the noun [fa:rt], is confronted with the task of assigning a meaning to it. The learner approaches this task by generating, on a purely phonological basis, a set of base candidates. The set contains all words which are phonologically transparent with respect to the input word.

\footnotetext{
${ }^{4}$ The definition is inspired by Saussure's notion of "phonetic species" (cf. Saussure 1916). Phonetic species are units whose identity is perceptually rather than articulatorily based. They are arrived at by abstracting away from all differences between speech sounds (Saussure's "phonemes") which are due to the articulatory organization of the syllable or to the influence of adjacent segments. For discussion, see Anderson (1985: 33ff.).
} 
The double arrow " $\Rightarrow$ " points from a word to its set of base candidates. Subsequently the semantic compatibility of these candidates with respect to the context in which the input word is encountered is evaluated. If there is a semantically compatible candidate, it is accepted as the base. Assuming that the candidate [fa:ron] is likely to be semantically compatible with the context in which the noun [fa:rt] is encountered, the meaning assigned to [fa:rt] in acquisition must refer to the meaning of [fa:ron]. As a result the pair Fahrt fahren will be semantically transparent.

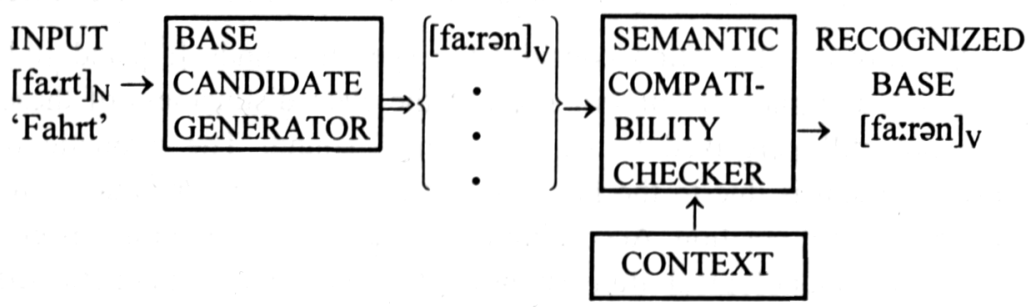

By contrast, for the noun [traxt] the etymological base [tra:gən] is not generated as a base candidate due to phonological opacity. As a result base recognition must fail and the meaning assigned to [traxt] in acquisition is determined by the context alone.

Consider next the question of why semantic stability is generally found only among etymologically related words. For example, the English noun growth is consistently interpreted in terms of its etymological base grow whereas the noun filth is not interpreted with reference to its etymologically unrelated base candidate fill. The answer to that question involves the notion of continuity, as defined in (9).

$\left.\begin{array}{lll}\text { (9) } & \text { (i) } & \mathrm{P}_{1}: \mathrm{A} \rightarrow \mathrm{B} \\ \text { and } & \text { (ii) } & \mathrm{P}_{2}: \mathrm{A} \Rightarrow\{\ldots, \mathrm{B}, \ldots\} \\ \text { then } & & \mathrm{P}_{2}: \mathrm{A} \rightarrow \mathrm{B}\end{array}\right\}$ continuity

If there is a speaker $P_{1}$, for whom (i) is true (i.e. a speaker who interprets word $A$ with reference to word $B$ ), and in the following generation a learner $\mathrm{P}_{2}$, for whom (ii) is true (i.e. a learner who generates word $B$ as a base candidate for word A), there is "continuity". The result of continuity is that candidate B is very likely to satisfy the Semantic Compatibility Checker and be recognized as the base of word A. This is because a speaker for whom (i) is true would normally use word A in a context with which word B is semantically compatible. As a result of being recursive the scheme in (9) entails that as long as 
continuity exists there will be semantic stability in the relation between words. Crucially, for etymologically related words there always exists a speaker " $\mathrm{P}_{1}$ ", namely, the coiner of word A. This is because newly coined words (especially abstract nouns) are generally based on, and interpreted in terms of, an existing word. Therefore, according to (9), the relation between etymologically related words will remain semantically stable for as long as one is generated as a base candidate of the other. ${ }^{5}$

The semantic relation between an abstract noun and its base is destabilized only if phonological changes render the pair phonologically opaque. This is because such changes have the consequence that $\mathrm{B}$ is no longer generated as a base candidate of $\mathrm{A}$. This point is illustrated in some detail in section 3 .

\section{Evidence for defining base candidates on phonological grounds}

The pairs in (2) differ from the pair in (1) in that they involve some alternation of the postvocalic consonant. In support of the phonologically based acquisition model in (8) we find that alternations are due to autonomous phonological

${ }^{5}$ Of course it occasionally happens that a candidate is accepted as the base even though it is not the etymological base. This is called "folk etymology" and can be depicted as follows:

(i) $\mathrm{P}_{1}: \mathrm{A} \rightarrow \mathrm{B}$

(ii) $\mathrm{P}_{2}: \mathrm{A} \Rightarrow\{\ldots, \mathrm{C}, \ldots\}$

$\mathrm{P}_{2}: \mathrm{A} \rightarrow \mathrm{C}$

While folk etymology cannot be predicted, the model in (8) makes explicit the circumstances which are conducive to its occurrence. First, the nonetymological base must satisfy the phonological criteria for being selected as a base candidate. Second, it must fit into the context in which the input word is typically encountered. An example are the words Bad 'bath' and baden 'bathe', which are not cognates in German. The etymological base of Bad, the rare verb bähen 'to warm, to heal with compresses', was no longer generated as a base candidate as a result of undergoing umlaut. (Umlaut was caused by the glide inserted to break up the hiatus, cf. OHG ba:en > ba.jen > bä.jen > bä.en.) By contrast, the historically unrelated form baden continued to be among the base candidates for Bad. The claim that that candidate at one point started to be accepted as the base is supported by the historical change in the meaning of Bad from 'healing with warm compresses' to 'bath' and by the change in the spelling of the noun from $<$ bat $>$ to $<$ bad $>$.

While folk etymology is apparently very common at an early stage in acquisition there are remarkably few instances of "established" folk etymology. This shows that semantic compatibility is normally satisfied only when continuity obtains. 
changes. Consider first the phonological rule in (10), which applied in Germanic and caused most of the fricative stop alternations in (2). ${ }^{6}$

$$
[- \text { son }] \rightarrow[+ \text { cont }] /{ }_{-}
$$

The historical spirantization rule (10) resulted in phonological opacity for any $t$-suffixation whose base has a postvocalic stop. An example is the pair Gift geben in (11). Words which satisfy the structural description of a rule are henceforth in bold; the "•" signifies that the form is reconstructed:

(11) a. Rule (10) causes alternation $\mathbf{G i}[\mathbf{f}] \mathbf{t} \sim \operatorname{ge}[\mathrm{b}] \mathrm{en}$ (•gha[bh]-) b. Rule (10) does not cause alternation $\mathrm{Fah}[\mathrm{r}] \mathrm{t} \sim \mathrm{fah}[\mathrm{r}] \mathrm{en}$

(•pe[r]-)

$\mathrm{Ja}[\mathrm{kt}]$ 'hunting' $\sim \mathrm{ja}$ [g]en 'hunt'

OHG ja[ga:]t ja[ga:]n

Rule (10) did not cause phonological opacity in the pair Fahrt fahren because neither cognate met its structural description. Similarly, that rule did not cause opacity in the pair Jagd $\sim$ jagen because at the time when the rule applied the postvocalic stop and the word-final $t$ were not adjacent (cf. (11b)). Rule (10) accordingly had the effect that the etymological bases disappeared from the base candidate list of some nouns (e.g. Gift), but not of others (e.g. Fahrt, Jagd).

Consider next Verner's Law, part of which is stated in (12a), and rhotacism, (12b):

(12) a.

$$
\mathrm{s} \rightarrow \mathrm{z} /-\left[\begin{array}{c}
\mathrm{V} \\
{[+ \text { stress }]}
\end{array}\right]
$$

b. $\quad \mathrm{z} \rightarrow \mathrm{r} / \mathrm{V}_{-} \mathrm{V}$

The rules in (12) caused the consonantal alternation in the pair List $\sim$ lehren, but did not cause any alternation in the pair Fahrt fahren. Crucially, the $r$ in lehren, unlike the $r$ in fahren, historically stems from an $s$ :

\footnotetext{
${ }^{6}$ This change is presumably due to a general constraint against coda clusters consisting of obstruents with identical values for the feature [continuant]. As a result of the change in (10), stop-stop clusters appeared as fricative-stop clusters. Similarly, there was a process in the history of English which caused fricatives to become stops if preceded by a fricative in coda position (cf. the final stop in height, weight, drift, craft, etc. compared to the final fricative in depth, width, length, truth, filth, etc.). Both rules changed [ $\alpha$ cont][ $\alpha$ cont] obstruent coda clusters to [+cont][-cont] clusters in accordance with sonority sequencing.
} 
(13) Rules (12a,b) cause alternation Rules (12a,b) do not cause alternation $\begin{array}{ll}\mathrm{Li}[\mathrm{s}] \mathrm{t} \sim \text { leh[r]en } & \text { Fah[r]t } \sim \text { fah[r]en } \\ (\bullet \text { lai }[\mathrm{s}]-) & (\bullet p e[\mathrm{r}]-)\end{array}$

Consider next the Germanic rule of mid-vowel raising in (14):

$$
\mathrm{e} \rightarrow \mathrm{i} / \mathrm{C}_{\mathrm{o}} \mathrm{i}
$$

Because all nouns in (1) and (2) originally ended in [i], mid-vowel raising caused alternations in the pairs involving a mid-vowel in Germanic, which includes all pairs in the middle and right columns in (2). By contrast, neither the words in the left column in (2), nor the pair in (1), met the structural description of mid-vowel raising with the result that no alternation arose.

(15) Rule (14) causes alternation: Rule (14) does not cause alternation:

$$
\begin{array}{ll}
\text { Pfl[I]cht } \sim \text { pfl[e]gen } & \text { Fahrt } \sim \text { fahren } \\
\text { (•pl[e]hti) } & (\bullet f[a] r t i)
\end{array}
$$

Although the pairs with low stem vowels in (2) were not affected by rule (14) they did subsequently become opaque due to the rule of vowel lengthening in (16):

$$
\left[\begin{array}{c}
\mathrm{V} \\
{[+ \text { stress }]}
\end{array}\right] \rightarrow \mathrm{V}: / \ldots
$$

Rule (16) affected both members of the pair Jagd jagen because it historically preceded syncope (cf. jaget $>$ ja.get $>$ ja.gt). Consequently, no alternation arose in that pair.

(17) Rule (16) causes alternation: Rule (16) does not cause alternation:

$$
\operatorname{Tr}[\mathrm{a}] \operatorname{cht} \sim \operatorname{tr}[\mathbf{a}:] \text { Sgen } \quad \text { j[a:]\$get } \sim \text { j[a:]\$gen }
$$

The MHG process of vowel lengthening in open syllables would have caused the pair Fahrt fahren to become opaque, if not for the coincident process which caused the vowels [a] and [e] to be lengthened before clusters consisting of $r$ followed by a coronal (cf. $B[\mathrm{a}] r t>B[\mathrm{a}:] r t$ 'beard', $S c h w[\mathrm{e}] r t>$ $S c h w[\mathrm{e}] r t$ 'sword', $H[\mathrm{e}] r d>H[\mathrm{e}] \mathrm{rd}$ 'hearth', etc.). This rule yielded a long vowel in the noun Fahrt, with the end result that the pair Fahrt $\sim$ fahren remained phonologically transparent:

$$
\text { F[a:]rt f }[\mathbf{a :}] \text { Sren }
$$


These examples indicate that autonomous phonological change causes opacity in some pairs but not in others. ${ }^{7}$ The autonomy of phonological change supports my hypothesis that it is the phonological form of words which determines base recognition and thereby semantic stability among cognates. To account for the observed correlations it is necessary to assume that words are stored in the mental lexicon with their surface phonological form.

\section{Empirical evidence for base recognition}

\subsection{Semantic diagnostics}

It is important to realize that it is semantic (in)stability among cognates, not semantic drift, which is predicted by the model of base recognition in (8). A pair which is semantically unstable may or may not drift. If neither member changes its meaning, unstable pairs may continue to exhibit semantic similarity as is illustrated in (19a):

(19) a. Frost $\sim$ frieren

'frost' 'freeze'

Schrift $\sim$ schreiben

'script' 'write'

Flucht $\sim$ fliehen

'flight' 'flee'

b. Germ.: Frost; Eng.: frost; Ice.: frost; Swe.: frost; Du.: vorst

Germ.: frieren; Eng.: freeze; Ice.: frjósa; Swe.: frysa; Du. vriezen

Semantic similarity among cognates within a language as in (19a) is of no greater theoretical significance than is semantic similarity among cognates in distinct languages as illustrated in (19b). A priori, neither phenomenon warrants any conclusions regarding the recognition of lexical relatedness but may simply be due to etymological relatedness in conjunction with relative constancy of the meaning developments of the individual words through time. By contrast, semantic stability, as manifested in parallel semantic changes, necessarily indicates that a word has been interpreted in terms of its base.

\footnotetext{
7 There is also non-autonomous phonological change, specifically analogical leveling. A prerequisite for leveling is the recognition of relatedness between words in spite of phonological opacity. Some conditions for systematic base recognition under such conditions are discussed in sections 5 to 7 .
} 
There is no evidence that any of the pairs in (19) are semantically stable. ${ }^{8}$ Therefore there is no reason to abandon the phonology-based explanation of the correlations observed in (3). ${ }^{9}$ The claim that semantic similarity among the cognates in (19) results merely from etymological relatedness along with the accidental absence of any drastic semantic changes rather than from base recognition does not preclude recognition of relatedness as a result of deliberate reflection. In fact, the sophisticate may well detect manifold aspects of semantic relatedness among the cognates in (2). Fleischer and Barz (1992) make much of such observations and distinguish various degrees of semantic relatedness in (2) from "less clear but still comprehensible" to "obscure" with some cases being classified as "marginal". Cases in which semantic relatedness is deemed to be "still comprehensible" are accounted for by positing wordinternal morpheme structure, thereby differentiating them from the entirely obscure cases. However, recognition of relatedness between words which are already associated with specific meanings by the mature speaker does not affect semantic interpretation. ${ }^{10}$ That is, the noun Tracht will continue to refer to costumes even if a speaker later comprehends its relatedness to the verb tragen. By contrast, base recognition as modelled in (8) refers to the situation in which a learner encounters a phonological form of unknown meaning. The model aims at describing conditions for assigning a semantic representation to such a newly acquired phonological form; specifically it aims at describing the conditions under which words are interpreted in terms of their (etymological) base. Continual satisfaction of those conditions will result in semantic stability between words.

\footnotetext{
${ }^{8}$ Suppose that the meaning of the verb frieren were to become restricted such that it requires a human agent. Intuitively, it seems unlikely that that change would be reflected in the semantic development of the noun Frost, which distinguishes the pair Frost $\sim$ frieren crucially from the pair Fahrt fahren described in (1).

${ }^{9}$ The only $t$-suffixations for which base recognition evidently succeeds in spite of phonological opacity involve polysyllabic stressed prefixes. Examples are Übereinkunft 'agreement' übereinkommen 'to agree', Zusammenkunft 'gathering' zusammenkommen 'to gather'. Apparently in such cases the prefix provides the crucial phonological link between the cognates. For monosyllabic stressed prefixes, such relations are not necessarily stable, cf. Zukunft 'future' zukommen 'to befit'. Prefixless cognates or cognates with unstressed prefixes which exhibit comparable phonological alternations are unstable, cf. Zunft 'guild' ziemen 'to be proper', Vernunft 'reason' vernehmen 'to examine a witness', etc.

${ }^{10}$ Similarly, the recognition of relatedness among cognates in different languages has no consequence for the semantic interpretation of words.
} 
To summarize, while semantic opacity is a clear indicator of failed base recognition in acquisition and semantic stability indicates successful base recognition, synchronic semantic similarity among cognates is of no linguistic significance.

\subsection{Morphological diagnostics}

The claim that the semantic similarity in (19) is accidental and must therefore be distinguished from semantic stability as illustrated in (1) is supported by an additional diagnostic for base recognition: the potential of a noun to be verbalized. The examples in (20) show that German monosyllabic or trochaic nouns for which base recognition fails are in principle subject to verbalization. As is illustrated in (20b), such verb formations frequently involve a prefix and/or phonological changes:

$$
\begin{array}{rlll}
\text { (20) a. } & \text { Neid } \rightarrow \emptyset & \text { 'envy' } & \text { b. (be)neiden 'to envy' } \\
\text { Eifer } \rightarrow \varnothing & \text { 'zeal' } & \text { (sich) ereifern 'to get excited about sth.' } \\
\text { Wut } \rightarrow \varnothing & \text { 'fury' } & \text { wüten 'to rage, to be furious' }
\end{array}
$$

By contrast, nouns for which base recognition succeeds do not yield acceptable verbs regardless of what prefixes or phonological changes are applied: ${ }^{11}$

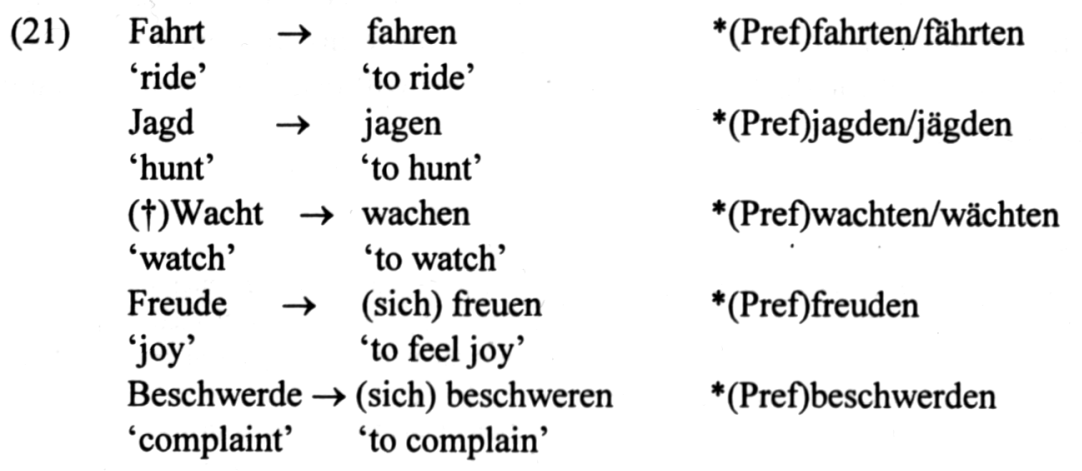

\footnotetext{
"Conversion is not necessarily a reliable diagnostic for base recognition. First, a seemingly converted verb may have entered the language through borrowing. Second, in some languages there are phonologically defined "niches of productivity" where regular morphological blocking fails to apply. For example, German words ending in [-or] can always be verbalized regardless of their relations to other words (e.g. Kälber 'calves' kälbern, milder 'milder' mildern, Schneider 'tailor' schneidern).
} 
Since base recognition is predicted to fail for the nouns in (2), verbalization should be possible in principle. Derived verbs are indeed attested for most of those nouns as is shown in (22):

(22)

$\begin{array}{llc}\text { schlachten } & \text { vergiften } & \text { buchten } \\ \text { betrachten } & \text { verpflichten } & \text { züchten } \\ \text { entlasten } & \text { überlisten } & - \\ \text { schäften } & \text { sichten } & \text { wuchten }\end{array}$

We thus find that base recognition as modelled in (8) is reflected not only in semantic stability but also in the applicability of verb formation. Returning now to the nouns in (19a), we find that verbalizations are attested for them as well, which indicates that base recognition indeed fails:

(23) beschriften

frösteln, entfrosten

flüchten

There is evidence that the same correlations between phonological transparency, semantic stability and potential noun-verb convertibility hold in English as well. Consider the rule in (24a) which affected all words in bold in (24b):

(24) a. V: $\rightarrow \mathrm{V} / \ldots C C$

b. causes alternation:

$$
\begin{array}{lll}
\text { drift } \sim \text { drive } & \text { trust } \sim \text { true } & \text { truth } \sim \text { true } \\
\text { thrift } \sim \text { thrive } & \text { health } \sim \text { heal } & \text { growth } \sim \text { grow } \\
\text { craft } \sim \text { crave } & \text { stealth } \sim \text { steal } & \text { flight } \sim \text { fly } \\
\text { shaft } \sim \text { shave } & \text { dearth } \sim \text { dear } & \text { height } \sim \text { high } \\
\text { rift } \sim \text { rive } & \text { birth } \sim \text { bear } & \text { warmth } \sim \text { warm }
\end{array}
$$

The nouns in the two leftmost columns in (24b), but not their respective bases, end in a cluster. Consequently, vowel length alternations arose. ${ }^{12}$ By contrast, the nouns in the rightmost column only end in a cluster if their base also ends in a cluster. Consequently, phonological transparency was preserved. This data again indicates that phonological opacity versus transparency is governed by autonomous phonological change. As is predicted by the model in (8), the nouns in (24) have mirrored the meaning changes in their etymological

\footnotetext{
${ }^{12}$ Perhaps some of these pairs were also disassociated by vowel lengthening in open syllables (cf. $\operatorname{sh}[\mathrm{a}] v e>\operatorname{sh}[\mathrm{a}:] v e$ ).
} 
bases only for as long as they have satisfied phonological transparency. Indeed all phonologically opaque pairs show clear signs of semantic drift.

As in German, noun to verb conversion is possible in principle only if base recognition fails, as in the phonologically opaque pairs in (25b):

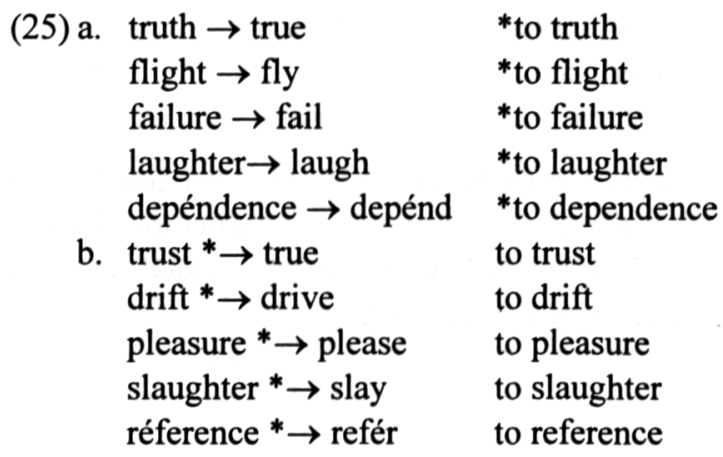

Crucially, phonological opacity is always the result of autonomous historical sound changes and must therefore be analyzed as the cause for both noun to verb conversion and semantic instability.

\section{Other types of relations}

The claim that the semantic drift among the cognates in (26a) reflects failed base recognition due to phonological opacity raises the question of why the pairs in (26b) are stable.

$$
\begin{aligned}
& \text { (26) a. drift }{ }^{*} \rightarrow \text { drive } \\
& \text { thrift } * \rightarrow \text { thrive } \\
& \text { craft } * \rightarrow \text { crave } \\
& \text { shaft } * \rightarrow \text { shave } \\
& \begin{array}{ll}
\text { b. } & \text { left } \rightarrow \text { leave } \\
\text { grew } \rightarrow \text { grow } \\
\text { made } \rightarrow \text { make } \\
\text { taught } \rightarrow \text { teach }
\end{array}
\end{aligned}
$$

The pairs in (26b) involve similar or even more isolated types of phonological alternation compared to those in (26a). Yet, they are semantically stable, which implies that base recognition has been successful. This difference regarding sensitivity to phonological conditions presumably reflects a difference in the type of relations. Whereas abstract nouns can be interpreted with reference to purely contextual information (cf. the interpretation of baseless nouns like zeal, envy) inflected forms can only be interpreted with reference to a base. The recognition, on the basis of syntactic clues, that a word is inflected 
activates an extended base search which is not limited by phonological form and is therefore likely to succeed. In contrast, the base search for monosyllabic abstract nouns succeeds only if there is a suitable, i.e. a phonologically transparent, base candidate.

While complete phonological transparency is clearly not a prerequisite for recognition of tense relations, onset identity is probably required. Apart from a few so-called suppletive pairs involving non-cognates (e.g. went $\rightarrow$ go $),{ }^{13}$ tense relations destabilized whenever onsets became opaque (cf. [r]ought ${ }^{*} \rightarrow$ [w]ork). ${ }^{14}$ Unfortunately, the evidence is not conclusive since alternations in word-initial position arose only rarely in English.

A clear case showing that inflectional relations can be sensitive to phonological transparency concerns plural-singular relations in English. Among the remaining phonologically opaque pairs we find that opacity is always restricted to a single segment. The pairs in (27a), for example, are opaque only with respect to a vowel and the pairs in (27b) are opaque only with respect to a consonant:

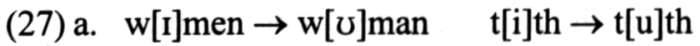

$$
\begin{aligned}
& \mathrm{m}[\varepsilon] \mathrm{n} \rightarrow \mathrm{m}[\mathrm{x}] \mathrm{n} \quad \mathrm{g}[\mathrm{i}] \mathrm{se} \rightarrow \mathrm{g}[\mathrm{u}] \mathrm{se} \\
& \text { ch[I]ldren } \rightarrow \text { ch[ar]ld } \quad \text { m[ar]ce } \rightarrow \text { m[au]se } \\
& \mathrm{f}[\mathrm{i}] \mathrm{t} \rightarrow \mathrm{f}[\mathrm{U}] \mathrm{t} \quad \mathrm{l}[\mathrm{ar}] \mathrm{ce} \rightarrow \text { l[av]se } \\
& \text { b. } \operatorname{mou}[ð] \mathrm{s} \rightarrow \operatorname{mou}[\theta] \quad \text { shel[v]es } \rightarrow \text { shel[f] } \\
& \text { hou[z]es } \rightarrow \text { hou[s]e cal[v]es } \rightarrow \text { cal[f] } \\
& \text { lea[v]es } \rightarrow \text { lea[f] wol[v]es } \rightarrow \text { wol[f] } \\
& \text { thie[v]es } \rightarrow \text { thie[f] scar[v]es } \rightarrow \text { scar[f] }
\end{aligned}
$$

All pairs which were opaque in both respects destabilized. The examples in (28a) are given in $\mathrm{OE}$ orthography, $\langle\mathrm{c}\rangle$ represents the palatal voiceless affricate.

\footnotetext{
${ }^{13}$ Suppletive pairs without any phonological similarities are never genuinely stable. The English comparative worse, for example, has over the last thousand years been variously associated with evil, ill, or bad. The former suppletive past tense form of go, i.e. eode, was replaced by another suppletive form, i.e. went. Why should the pair went $\sim$ go be any more stable than eode $\sim$ go?

${ }^{14}$ The onsets became opaque because metathesis "fed" $w$-deletion before $r$ in wrought.
} 


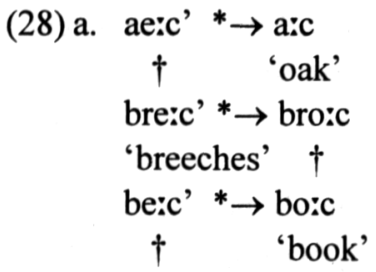
b. $\quad[\text { ste:vz }]^{*} \rightarrow[$ stæf $]$
'staves' 'staff'
$[\text { kli:vz }]^{*} \rightarrow$ [klif]
$\dagger \quad$ 'cliff'
$[\mathrm{klo:ðz}]^{*} \rightarrow[\mathrm{klp} \theta]$
'clothes' 'cloth'

Destabilization in the pairs in (28) manifests itself in the development of backformed singulars (e.g. stave), the development into pluralia tantum (e.g. clothes, breeches), the fact that forms became obsolete (e.g. cleeves, brook), and the development of innovative plural forms (e.g. staffs, oaks).

Assuming that lack of phonological transparency caused the destabilization of the pairs in (28), the question arises of why those pairs, but not the pairs in (27), became "doubly opaque". The crucial difference between the umlaut pairs in (27a) and those in (28a) concerns the place of articulation of the postvocalic consonant. The singular forms in (28a) have a back vowel followed by a velar stop, which, due to umlaut, was subject to palatalization in the corresponding plural forms. The result was that the pairs became doubly opaque and destabilized. This phonological account of destabilization also explains a gap in the stable umlaut pairs in (27a): there are no pairs involving postvocalic velars.

All voicing alternations in $(27 \mathrm{~b})$ and $(28 \mathrm{~b})$ reflect a rule of fricative voicing in medial onset position which applied at a time when the plurals were still disyllabic. At that time, the plurals were also susceptible to vowel lengthening in open syllables. That rule caused no alternations in the plurals in (27b) because their vowel was either already long (cf. the pairs in the left-hand column in (27b)), or the first syllable was closed (cf. the pairs in the right-hand column in (27b)). By contrast, vowel lengthening did cause additional opacity in staves $\sim$ staff and cleeves $\sim$ cliff since the plurals originally had a short vowel in open syllables. In the pair clothes $\sim$ cloth, vowel opacity is due to a rule which shortened back mid vowels before the interdental fricative (cf. broth, moth, etc.). It is because of these purely phonological differences that all pairs in (28b), but none in (27b), became doubly opaque and destabilized.

The data in (27) and (28) suggest then that plural singular pairs in English can remain stable even when developing a rare or isolated alternation (cf. $w[\mathrm{I}]$ men $\sim w[\mathrm{v}]$ man, $g[\mathrm{i}] s e \sim g[\mathrm{u}] s e$ ) whereas such pairs necessarily destabilize when developing multiple alternations. This observation supports the claim that base recognition is subject to phonological restrictions which refer to the surface form of words as shown in (29): 


\begin{tabular}{|ll|}
\hline Type of relation: & Phonological transparency conditions: \\
\hline plural $\sim$ singular & $\begin{array}{l}\text { a. consonants } \\
\text { b. word-initial minimal word }\end{array}$ \\
\end{tabular}

The transparency conditions in (29) are disjunctive: to maintain stability, plural $\sim$ singular relations in English must be transparent either with respect to all consonants, or with respect to the initial minimal word, which includes the onset and at least two moras. As was argued earlier, recognition of tense relations may depend on identical onsets. ${ }^{15}$ Returning to the model of base recognition in (8), inflected forms function as triggers of an extended base search, with relaxed phonological transparency conditions. The conditions which determine the set of base candidates for an inflected form depend on the specific type of inflectional relation (e.g. tense, number) as is illustrated in (29).

The conditions on semantic stability noted here cannot be explained in a Generative model where relatedness between words is expressed by specifying rules (including so-called "allomorphy rules" or "readjustment rules") with which they are derived from a common underlying form. Indeed any model which posits abstract morphemes as meaning-bearing units is incompatible with a dependence of acquisition of word meaning on surface phonological forms. A further shortcoming of Generative approaches to morphophonology is the failure to distinguish different types of morphological relations. Instead, the positing of phonological rules to relate words depends on the frequency of the respective alternations. Such an approach raises the question of why the pairs in (26a) and (28b), which involve recurrent alternations, destabilized whereas the pairs in (26b) and (27a), some of which involve isolated alternations, have been stable.

\section{Conditions on partial transparency in derivational relations}

To be sure, not only inflectional but also derivational relations may be semantically stable in spite of partial phonological opacity as is illustrated with the pairs in (30b).

\footnotetext{
${ }^{15}$ Note that although being confined to certain aspects of phonological structure, the relevant conditions nonetheless require transparency in the surface phonological form of words.
} 


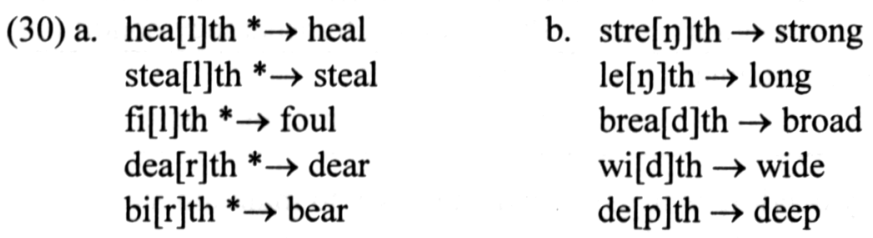

The claim that the pairs in (30b) are genuinely stable is supported by their histories. The adjective strong, for instance, also meant 'strict' in OE (cf. German streng) and strength also meant 'strictness'. The fact that both cognates lost that meaning and developed in a parallel fashion indicates a semantically stable relation. What distinguishes the pairs in (30b), which are stable in spite of phonological opacity, from those in (30a), in which phonological and semantic opacity correlate?

On the present approach to base recognition, the first place to look for a relevant difference is in the phonological form. In the pairs in (30a) the wordfinal fricative is preceded by a liquid or a homorganic nasal, thereby conforming to the restrictions exhibited by underived English words as shown in (31): ${ }^{16}$

(31) a. X liquid fricative \#

$$
\text { b. } \mathrm{X}\left[\begin{array}{l}
\text { nasal } \\
\alpha \text { place }
\end{array}\right]\left[\begin{array}{l}
\text { fricative } \\
\alpha \text { place }
\end{array}\right] \#
$$

$$
\begin{aligned}
& \text { golf, valve, dwarf, curve, earth, } \\
& \text { north, belch, birch } \\
& \text { labyrinth, absinthe, cringe, } \\
& \text { branch, nymph, triumph }
\end{aligned}
$$

The relevant cluster restrictions largely reflect the well-known observation that sonority normally decreases in syllable codas. ${ }^{17}$ All coda clusters in (30b) violate either sonority sequencing or the condition that nasals must be homorganic to a following obstruent. These violations arguably alert learners to the derived status of the words in (30b). Because they recognize that the words are derived, learners activate an extended base search for which the conditions for generating base candidates are relaxed such that sameness of the consonantal structure suffices. ${ }^{18}$ As a result, base recognition succeeds for the pairs in (30b), but not for the pairs in (30a), even though all pairs involve the same type

\footnotetext{
${ }^{16}$ This restriction does not concern the coronal fricative which can be preceded by other consonants in coda position (e.g. box, blitz). This special status of coronals with respect to sonority sequencing is sometimes described in terms of extrasyllabicity.

${ }^{17} \mathrm{Cf}$. the Coda Law in Vennemann (1988).

${ }^{18}$ In dialects where width is pronounced [wi $\theta$ ] the extended base search is not activated and base recognition is predicted to fail.
} 
of opacity (i.e. opaque vowels) and are historically derived by the same suffix. $^{19}$

Speaker intuitions regarding relatedness between strength and strong should accordingly not be described by positing vowel changing rules which allow derivation from a common underlying form. Rather these intuitions are best captured by including the surface form of both words in the lexicon and by specifying the phonological conditions which determine base recognition.

\section{The role of inflectional "allomorphy" in the base recognition of deriva- tionally related words}

Consider the relations between the German abstract feminine nouns and their adjectival base in (32a):

$\begin{array}{llll}\text { a. } & \text { b. } & \text { c. } & \text { d. } \\ \begin{array}{l}\text { Stille } \rightarrow \text { still } \\ \text { 'silence' 'silent' }\end{array} & \text { OHG stilli: } & \text { ?Stillheit } & \text { †stilheit } \\ \begin{array}{l}\text { Schwere } \rightarrow \text { schwer } \\ \text { 'heaviness', 'heavy' }\end{array} & \text { OHG swa:ri: } & \text { ?Schwerheit } & \dagger \text { tswærheit } \\ \begin{array}{l}\text { Tiefe } \rightarrow \text { tief } \\ \text { 'depth' }\end{array} & \text { OHG tiufi: } & \text { ?Tiefheit } & \text { †tiefheit } \\ \begin{array}{l}\text { Reife } \rightarrow \text { reif } \\ \text { 'ripeness' 'ripe' }\end{array} & \text { OHG ri:fi } & \text { ?Reifheit } & \text { †rîfheit } \\ \begin{array}{l}\text { Strenge } \rightarrow \text { streng } \\ \text { 'strictness' 'strict' }\end{array} & \text { OHG strengi: } & \text { ?Strengheit } & \text { †strengheit } \\ \begin{array}{l}\text { Milde } \rightarrow \text { mild } \\ \text { 'mildness' 'mild' }\end{array} & \text { OHG mildi: } & \text { ?Mildheit } & \text { †mildekeit }\end{array}$

The morphological process relating the words in (32a) is entirely unproductive in modern German as can be inferred from the unacceptability of nonce formations ('Feine $\sim$ fein 'fine', *Dumme $\sim$ dumm 'dumb', etc.). All existing pairs are already attested at earlier stages of the language (cf. (32b)). The claim that the pairs are semantically stable in spite of their fossilized morphology is supported by their semantic developments. The adjective still, which used to refer to movement (e.g. 'standing', 'immobile'), now means 'silent, quiet'.

\footnotetext{
${ }^{19}$ Additional conditions triggering an extended base search in derivationally related words and the specific transparency conditions required are investigated in Raffelsiefen (forthcoming).
} 
This development is mirrored in the noun Stille 'silence, quiet'. The claim that base recognition succeeds for the pairs in (32a) is further supported by the fact that the abstract nouns ending in - $e$ block the productive rule of -heit-suffixation (cf. (32c)). The productivity of that rule can be inferred from its application to loan words (e.g. Tristheit, Laxheit, Robustheit), but -heit-formations relating to the adjectives in (32) are not listed in unabridged German dictionaries and are in fact unacceptable. Remarkably, the fossilized abstract nouns in - $e$ not only block the productive rule of -heit-suffixation but even "ousted" such MHG formations from the lexicon (cf. (32d)).

The examples in (32a) contrast with those in (33a), for which base recognition fails. The resulting semantic instability has manifested itself in more or less drastic semantic drift as the examples will illustrate. The nouns in (33a) furthermore fail to block -heit-suffixations as shown by the forms in (33c):

\begin{tabular}{|c|c|c|c|}
\hline a. & & b. & c. \\
\hline $\begin{array}{l}\text { Fläche } \\
\text { 'surface' }\end{array}$ & 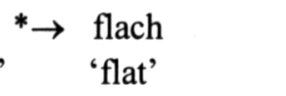 & MHG vleche & Flachheit \\
\hline $\begin{array}{l}\text { Höhle ' } \\
\text { 'cave' }\end{array}$ & ${ }^{*} \rightarrow \begin{array}{l}\text { hohl } \\
\text { 'hollow' }\end{array}$ & OHG huli: & Hohlheit \\
\hline $\begin{array}{l}\text { Sänfte } \\
\text { 'sedan (c) }\end{array}$ & $\begin{array}{l}* \rightarrow \text { sanft } \\
\text { chair)' 'gentle' }\end{array}$ & OHG samfti: & Sanftheit \\
\hline $\begin{array}{l}\text { Klemme } \\
\text { 'clamp' }\end{array}$ & $* \rightarrow$ klamm & MHG klemme & Klammheit \\
\hline $\begin{array}{l}\text { Fäule } \\
\text { 'rot' }\end{array}$ & $\begin{array}{ll}* \rightarrow & \text { faul } \\
& \text { 'lazy, rotten' }\end{array}$ & OHG fuli: & Faulheit \\
\hline $\begin{array}{l}\text { Güte } \\
\text { 'kindness }\end{array}$ & 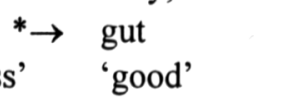 & OHG guoti: & Gutheit \\
\hline
\end{tabular}

Semantic instability in (33a) correlates with vowel alternations due to the historical rule of umlaut. In OHG, $i$-suffixation always resulted in umlaut. The fact that umlaut caused opacity in the pairs in (33a), but not in (32a), results from the phonological structure of the words in question. Most words in (32a) had a non-back stem vowel which was unaffected by umlaut (e.g. Tiefe $\sim$ tief). Others related to an adjective belonging to the $j a$-stems, which were affected by umlaut themselves (cf. swari $>$ swari) with the result that no opacity arose (e.g. Schwere $\sim$ schwer). By contrast, umlaut caused opacity in all pairs in (33), due to the back vowel in the base. 
The observation that umlaut destabilized the relations in (33a) is significant because umlaut alternations occur in hundreds of stable relations in German. But these relations differ from the one illustrated in (33) in that they either concern inflectional pairs (cf. $(34 \mathrm{a}, \mathrm{b}))$, or are related by a productive morphological rule (cf. (34c)) $:^{20}$

$$
\begin{aligned}
& \text { a. b. } \quad \text { c. } \\
& \text { älter } \rightarrow \text { alt } \quad \text { Hühner } \rightarrow \text { Huhn Stühlchen } \rightarrow \text { Stuhl } \\
& \text { 'older' 'old' 'hens' 'hen' 'little chair' 'chair' } \\
& \text { jünger } \rightarrow \text { jung Bälle } \rightarrow \text { Ball Lämpchen } \rightarrow \text { Lampe } \\
& \text { 'younger' 'young' 'balls' 'ball' 'little lamp' 'lamp' } \\
& \text { länger } \rightarrow \text { lang Söhne } \rightarrow \text { Sohn Compüterchen } \rightarrow \text { Computer } \\
& \text { 'longer' 'long' 'sons' 'son' 'little computer' 'computer' }
\end{aligned}
$$

The semantically stable word pairs in (35a) seem to contradict the claim

\begin{tabular}{|c|c|c|c|c|}
\hline & \multicolumn{3}{|c|}{ a. $\quad$ b. } \\
\hline $\begin{array}{l}\text { Schwäche - } \\
\text { 'weakness' }\end{array}$ & $\begin{array}{l}\text { schwach } \\
\text { 'weak' }\end{array}$ & MHG sweche & ?Schwachheit & $\dagger$ swachheit \\
\hline $\begin{array}{l}\text { Schärfe } \rightarrow \\
\text { 'sharpness' }\end{array}$ & $\begin{array}{l}\text { scharf } \\
\text { 'sharp' }\end{array}$ & OHG scarphi: & ?Scharfheit & $\dagger$ scharpfheit \\
\hline $\begin{array}{l}\text { Kürze } \rightarrow \\
\text { 'shortness' }\end{array}$ & $\begin{array}{l}\text { kurz } \\
\text { 'short' }\end{array}$ & OHG kurzi & ?Kurzheit & †kurzheit \\
\hline $\begin{array}{l}\text { Stärke } \rightarrow \\
\text { 'strength' }\end{array}$ & $\begin{array}{l}\text { stark } \\
\text { 'strong' }\end{array}$ & OHG starchi: & ?Starkheit, & $\dagger$ starcheit. \\
\hline $\begin{array}{l}\text { Nähe } \quad \rightarrow \\
\text { 'nearness' }\end{array}$ & $\begin{array}{l}\text { nah } \\
\text { 'near' }\end{array}$ & OHG na:hi: & ?Nahheit & †nâchheit \\
\hline $\begin{array}{l}\text { Höhe } \\
\text { 'height' }\end{array}$ & $\begin{array}{l}\text { hoch } \\
\text { 'high' }\end{array}$ & OHG ho:hi: & ?Hochheit & †hôchheit \\
\hline
\end{tabular}
that failed base recognition due to the umlaut alternation leads to semantic instability in unproductive derivational morphology. Furthermore, they show the same blocking effect as did the phonologically transparent pairs in (32a) as is manifested by the disappearance of the competing MHG -heit-suffixations in (35d):

The crucial difference between the unstable pairs in (33) and the stable pairs in (35) concerns the comparative forms of the adjectives. The comparative forms

\footnotetext{
${ }^{20}$ Productivity may also account for semantic stability in pairs like Scham 'shame' schämen 'to feel ashamed' since noun to verb conversion is still productive in German.
} 
of the adjectives in (33a) never show umlaut, but all of the comparative forms of the adjectives in (35) have undergone umlaut. This difference is due to the distinct comparative suffixes in OHG: the suffix -oro failed to cause umlaut, whereas the suffix -iro with its initial front vowel always caused umlaut as is illustrated in (36):

$$
\begin{array}{ll}
\text { a. OHG -oro } & \text { b. OHG -iro } \\
\text { flacher } \rightarrow \text { flach } & \text { schwächer } \rightarrow \text { schwach } \\
\text { hohler } \rightarrow \text { hohl } & \text { schärfer } \rightarrow \text { scharf } \\
\text { sanfter } \rightarrow \text { sanft } & \text { kürzer } \rightarrow \text { kurz } \\
\text { klammer } \rightarrow \text { klamm } & \text { stärker } \rightarrow \text { stark } \\
\text { fauler } \rightarrow \text { faul } & \text { näher } \rightarrow \text { nah } \\
\text { besser } \rightarrow \text { gut } & \text { höher } \rightarrow \text { hoch }
\end{array}
$$

Because base recognition in the relation between a comparative form and its base is subject to relaxed phonological transparency conditions (cf. the cases in (34)), the relations in (36b) are systematically recognized despite the vowel alternations. Once those relations are recognized, they systematically influence base recognition of the abstract nouns investigated here. Specifically, the umlauted comparative forms satisfy phonological transparency with respect to the abstract nouns (cf. the structure in bold in (37)), thereby providing the crucial link between those nouns and their etymological bases. This account presupposes that recognition of relatedness is transitive.

$$
\begin{array}{rlr}
\text { (37) a. } & \text { Fläche } \rightarrow \varnothing & \text { b. Schwäche } \rightarrow \text { (schwächer } \rightarrow \text { schwach) } \\
\text { Höhle } \rightarrow \varnothing & \text { Größe } \rightarrow \text { (größer } \rightarrow \text { groß) } \\
\text { Sänfte } \rightarrow \varnothing & \text { Härte } \rightarrow \text { (härter } \rightarrow \text { hart) }
\end{array}
$$

These data show that umlaut alternations regularly destabilize derivational relations like those in (33), unless there exist inflected umlauted forms which link the abstract noun to its base. ${ }^{21}$

${ }^{21}$ Additional evidence showing that phonological opacity due to umlaut hinders base recognition of abstract nouns is given in (i).
(i) Naht $\sim$ nähen (OHG na:en)
'seam' 'to sew'
Glut $\sim$ glühen (OHG gluoen)
Saat säen (OHG sa:en)
'red fire' 'to glow'
'seed' 'to sow'
Brut $\sim$ brühen (?OHG bruoen (not attested))
Draht $\sim$ drehen (OHG dra:en)
'brood' 'to scald'
'wire' 'to turn'
Mut $\sim$ mühen (OHG muoen)
'courage' 'to strive'

All pairs in (i) involve unproductive morphology. Fleischer and Barz err when they treat pairs like Fahrt $\sim$ fahren and Naht $\sim$ nähen on a par, claiming that they both are phonologically 


\section{Conclusion}

I have argued that a stable semantic relationship between cognates over historical time requires that each generation of language learners is able to recognize the base of the derived form. Base recognition is determined by specific phonological transparency conditions, which vary according to the type of morphological relation, but which always refer to surface phonological forms. I have also presented evidence that noun to verb conversion is possible only if the base of the noun is not recognized.

A description of the observed correlations between phonological transparency, semantic stability, and noun to verb conversion requires a model where all words which do not involve synchronically productive affixes are lexically listed in their surface phonological form. Associations between these words are captured by specifying conditions which govern the systematic recognition of word relatedness by language learners. The correlations cannot be expressed by a model where lexical relatedness between words is described by specifying rules with which they are derived from a common underlying form.

\section{REFERENCES}

Anderson, Stephen R. 1985. Phonology in the Twentieth Century. Chicago: University of Chicago Press.

Fleischer, Wolfgang and Irmhild Barz. 1992. Wortbildung der deutschen Gegenwartssprache. Tübingen: Max Niemeyer.

Raffelsiefen, Renate. 1993. "Relating words: a model of base recognition: part 1". Linguistic Analysis 23.3-159.

. Forthcoming. "Relating words: a model of base recognition: part 2". To appear in Linguistic Analysis.

Saussure, Ferdinand de. 1916. Cours de linguistique générale. Paris: Payot.

Vennemann, Theo. 1988. Preference Laws for Syllable Structure and the Explanation of Sound Change. Berlin: Mouton de Gruyter.

transparent (cf. 1992: 198). Pairs which involve umlaut alternations lack transparency, and relations between abstract nouns and their base destabilize under this condition (for the cause of the umlaut alternations in (i), see footnote 5). The observation that the pair Naht nähen, but none of the other pairs in (i), shows signs of semantic stability is perhaps due to the fact that Naht is the only noun whose plural form has an umlaut identical to the corresponding verb (i.e. Nähte), which may accordingly serve as a link for base recognition. 